\title{
Estimation Method to Achieve a Noise Reduction Effect of Airfoil with a Serrated Trailing Edge for Wind Turbine Rotor
}

\author{
Jaeha Ryi and Jong-Soo Choi \\ Additional information is available at the end of the chapter
}

http://dx.doi.org/10.5772/intechopen.73608

\begin{abstract}
This chapter describes a wind tunnel experiment that was undertaken to investigate the changes in the aerodynamic performance of a wind turbine due to the inclusion of a 2-Dimension (2D) airfoil with a serrated trailing edge designed to reduce the noise caused by a wind turbine rotor blade. The restrictive condition for the serrated trailing edge equipped with the use of a 2D airfoil was examined through the use of a wind tunnel experiment after studying existing restrictive condition and analyzing prior research on serrated trailing edges. The study was conducted according to Howe's theory, which is a cornerstone of the study of noise reduction effects produced by a serrated trailing edge. For the serrated trailing edge equipped on a 2D airfoil, the wake distribution and the relation to noise were analyzed in order to determine the restrictive condition in accordance with Howe's theory. The results indicated that an empirical formula or a theoretical approach should consider changes in the boundary layer thickness of a 2D airfoil, so an empirical noise prediction formula is suggested for the serrated trailing edge. Also, a comparison and an analysis of the prediction and the experimental results for the noise produced by the NACA0012 or the baseline airfoil equipped with a serrated trailing edge suggested a novel formula for a 2D airfoil. Finally, the 2D airfoil noise data are compared with wind tunnel test data by using an empirical formula estimation method.
\end{abstract}

Keywords: wind turbine noise, trailing edge serration, wind tunnel test, 2D airfoil noise test, noise reduction effect 


\section{Introduction}

Studies on serrated trailing edges have been conducted in order to find solutions to noise problems in the wind turbine rotor field. In 1991, Howe [1] suggested a theory to predict noise reduction in a $2 \mathrm{D}$ airfoil with a serrated trailing edge. He defined the variables depending on the shapes of the edges and identified differences in noise reduction depending on various aspect ratios of serrated trailing edges. Based on Howe's serrated trailing edge theory, Braun [2] confirmed in 1999 that noise produced by a wind turbine rotor could be reduced by the application of a serrated trailing edge with a diameter of $16 \mathrm{~m}$, and observed that changes in the frequency domains of noises occurred depending on the installation angles of serrated trailing edges.

In 2009, Gruber and Joseph [3] reported the noise reduction effect and the boundary layer thickness of a serrated trailing edge on a 2D airfoil by designing a 2D airfoil based on Howe's theory. Oerlemans et al. [4] applied a serrated trailing edge to a $2.3 \mathrm{MW}$ wind turbine rotor to observe noise changes, and used the beam-forming method to confirm noise changes.

From 2010 to the current, Phillip [5] has been conducting a wind tunnel test on a sawtoothshaped trailing edge and a slit-shaped trailing edge, and has confirmed the noise reduction effect and predicted noise changes based on Howe's theory. Michel Roger [6] carried out a wind tunnel test on five types of blush-shaped trailing edges. Based on the cross-section of the 2D airfoil of NACA65(12)-1, changes in the frequency components caused by variations in wake and flow were recorded using a hot-wire anemometer. In 2012, Dennis Y.C. Leung [7] applied a trailing edge with a $0^{\circ}$ angle of attack to a $2 \mathrm{D}$ airfoil, and confirmed noise reduction effects owing to changes in the aspect ratio of serrated trailing edges.

As mentioned above, the theoretical background of the previous studies was based on Howe's theory, but among the experiments involving wind tunnel tests and the actual wind turbine rotor tests, none showed improvements in both aerodynamic performance and noise performance simultaneously. Also, the studies on the noise reduction effect of serrated trailing edges only confirmed the noise reduction effects, while most of the studies on aerodynamic performance also only showed changes in noise performance.

This study aimed to examine changes in both aerodynamic performance and noise reduction by applying serrated trailing edges to $2 \mathrm{D}$ airfoils in a wind tunnel experiment. Also, this study proposes a prediction model for noise reduction effects with the use of serrated trailing edges, based on the experimental results obtained from the wind tunnel test.

\section{Theoretical background of trailing edge serration}

\subsection{Noise reduction mechanism of trailing edge serrations}

The noise reduction mechanism of trailing edge serrations was introduced by Howe based on an experiment on trailing edge noises in a 2D airfoil [1]. Figure 1 shows the shape-related variables of 


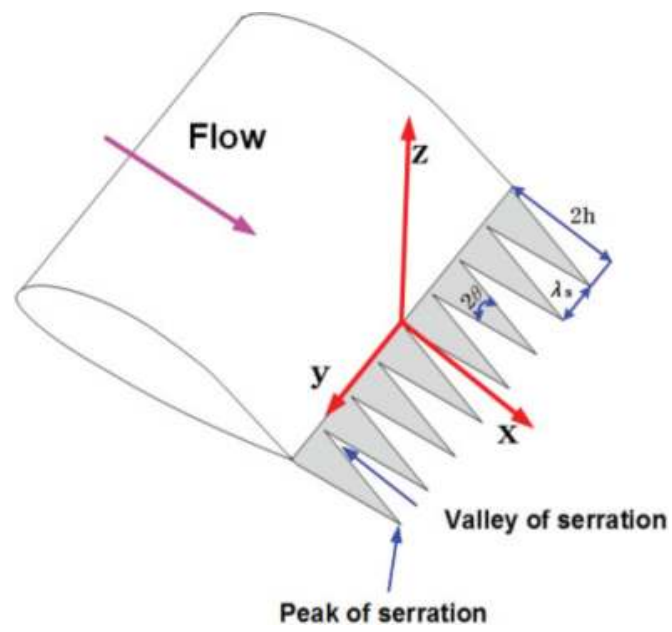

Figure 1. Turbulent flow over a serrated trailing edge [1].

serrated trailing edges applied to 2D airfoils in this study. The noise reduction effects of the serrated trailing edges were defined with the following criteria: span-wise wavelength $(\lambda s)$, amplitude of serrations $(\mathrm{h})$, incline angle $(\theta)$, main stream velocity $(\mathrm{U})$, and acoustic frequency $(\omega)$.

Howe's theory of the noise reduction effect induced by the use of trailing edge serrations is based on the following preconditions:

1. The airfoil of a serrated trailing edge has a plate shape, and the span of a rotor blade is infinitive.

2. Noises are produced by the turbulent components that pass through the trailing edge with a $0^{\circ}$ angle of attack, under the condition that noises are only present in the trailing edge.

3. The Kutta condition is met, and the flow that passes through the plate-shaped airfoil has a low Mach number.

4. Under the same flow conditions, the ratios between the amplitude of serrations and the boundary layer thickness and the wake of 2D airfoils are constant.

Based on the above preconditions, Howe [1] proposed an equation for noise reduction accomplished by serrated trailing edges. Eq. (1) is a function which defines the noise reduction effect $(\Psi(\omega))$ induced by trailing edge serrations with boundary layer thickness $(\sigma)$, span-wise wavelength $(\lambda)$, and blade-tip clearance based on the turbulent fluctuation frequency $(\omega)$ [1].

$$
\Psi(w)=\left(1+\frac{1}{2} \epsilon \frac{\partial}{\partial \epsilon}\right) f\left(\frac{w \delta}{U_{c}}, \frac{h}{\lambda}, \frac{h}{\delta} ; \epsilon\right)
$$

Eq. (2) was created with the root-to-tip distance set at " $h \geq 0$ ", for the case in which a serrated trailing edge is not used. 


$$
\Psi_{0}(w)=\left(w \delta / U_{c}\right)^{2} /\left[\left(w \delta / U_{c}\right)^{2}+\epsilon^{2}\right]^{2}
$$

The noise reduction effects of serrated trailing edges are produced by changes in the noise components of the turbulent boundary layers of $2 \mathrm{D}$ airfoils. At this time, the turbulence-induced frequency is assumed to meet the condition, and the changes in the turbulent boundary layer of serrated trailing edges resulted in the reduction of noises greater than the minimum. Also, under the same boundary layer conditions, the varying noise reduction effects depend on the different aspect ratios of serrated trailing edges $[1,8]$.

However, when a plate-shaped serrated trailing edge was applied to a 2D airfoil in an actual experiment, it is impossible to meet the preconditions proposed by Howe, which entail an experimental environment with a $0^{\circ}$ angle of attack and a constant ratio between the blade-tip clearance and the boundary layer thickness of serrated trailing edges.

In this study, the authors confirmed the preconditions proposed by Howe for the noise reduction effect brought about by the use of serrated trailing edges, and identified the factors restricting the noise reduction effects when a serrated trailing edge is applied to a $2 \mathrm{D}$ airfoil in a wind tunnel test. Also, the study proposed a model that predicts airfoil self-noises. In addition, the study utilized the wind tunnel test results to review the validity of the noise prediction empirical model for 2D airfoil self-noises, which was introduced by Brooks.

\section{Experimental apparatus and procedures}

\subsection{2-Dimension airfoil noise test}

This study conducted a wind tunnel test on 2D airfoils in a closed test section with a size of $1.25 \times 1.25 \mathrm{~m}$ by using the subsonic anechoic wind tunnel test facility at Chungnam National University. The wind tunnel experimental apparatus was set up to measure aerodynamic performance and noise reduction, as seen in Figure 2. To assess the aerodynamic performance of 2D airfoils, a three-axis balance was used, whereas a pressure scanner system with 50 pressure holes and 50 channels was installed in order to measure the pressure distribution. Also, a microphone system with a total of seven channels was installed to measure noises, as shown in Figure 3. A wind tunnel experiment was measured in the low-speed semi-anechoic wind tunnel at Chungnam National University. The volume of the anechoic chamber was $211.9 \mathrm{~m}^{3}$ and the tapered anechoic chambers had a cut-off frequency of $150 \mathrm{~Hz}$ [9].

Figure 4 shows the 2D cross-section of the experimental models with a downscaled radius $75 \%$ as large as the size of an actual rotor. The rotor blade had a chord length of $0.35 \mathrm{~m}$ and a span of $1.249 \mathrm{~m}$, and it was made of 60-class aluminum in order to minimize the possible structural vibrations and noises of the experimental models during the wind tunnel test. The model was installed with a structure supporting both ends (by fixing the upper and lower blades) and on a turn table with $360^{\circ}$ rotation, and the wind tunnel velocity and airfoil angles of attack could 


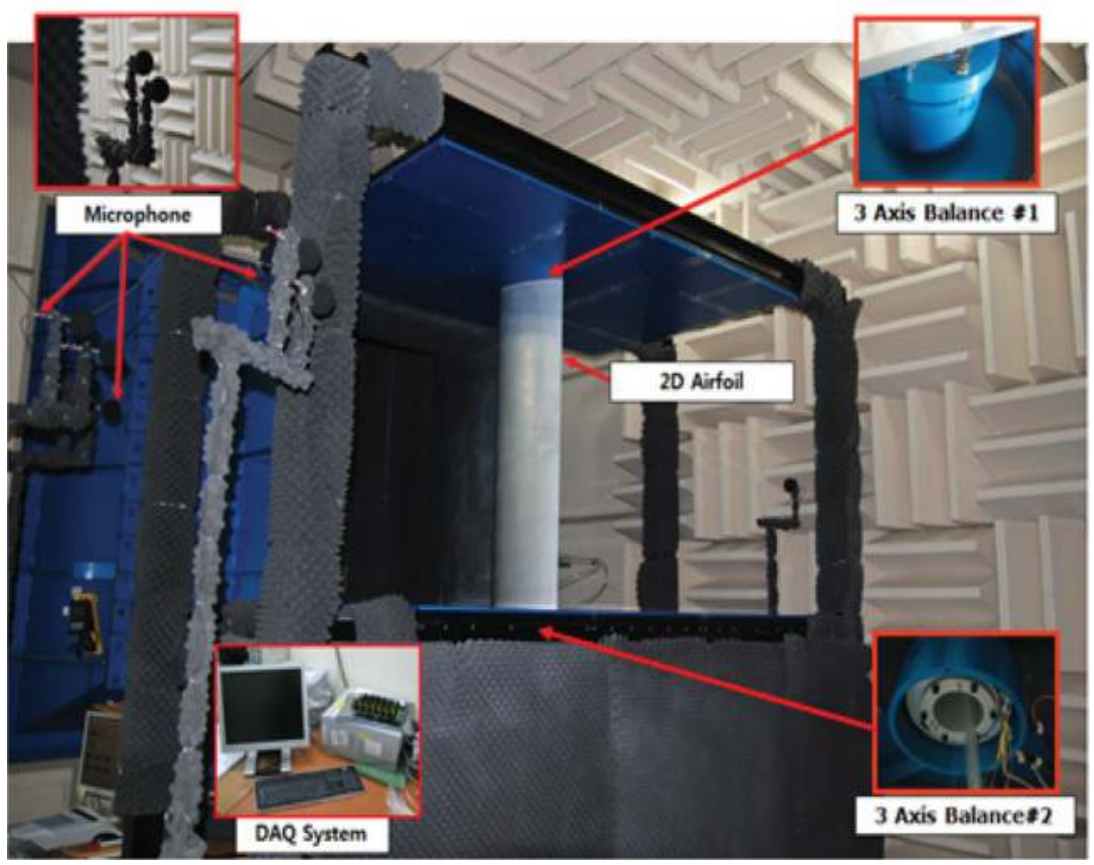

Figure 2. Configuration of wind tunnel test stand for airfoil experiment.

be adjusted depending on the experimental conditions. The aerodynamic performance of the experimental models was measured during the experiment by installing 2EA of three-axis balance. The aerodynamic performance and noise performance were simultaneously measured by installing each three-axis balance in the upper and lower part of the wind tunnel test section and by fixing both tips of the experimental model. The noise performance test was conducted with a wind velocity of about $30 \mathrm{~m} / \mathrm{s}(\mathrm{RE}=700,000)$ and a Reynolds number in consideration of the downscaling of the rotor radius to $75 \%$ of actual size. Noises were measured with a total of seven microphones, which were installed 1750 and $1830 \mathrm{~mm}$ away from the trailing edge of the blade. In the 2D airfoil experiment, Figure 5 shows the total of 7 types of serrated trailing edges were tested together with airfoils; basic information about the shapes of serrated trailing edges is described in Table 1. The wind tunnel test on 2D airfoils was conducted in an open experimental section in order to measure the aerodynamic performance and noise performance at the same time. In this case, precise calibration of the open experimental section was necessary to measure aerodynamic performance. Wind tunnel tests in open experimental sections are often subject to a simultaneous occurrence of flow stream line curvature and down-wash deflection phenomena, which rarely happens in free-air conditions. These phenomena resulted in a decrease in the angles of attack and the lift curve slope of the 2D airfoils, and caused drag-changing shapes. The calibration methods suggested by Brooks \& Marcolini [11] 


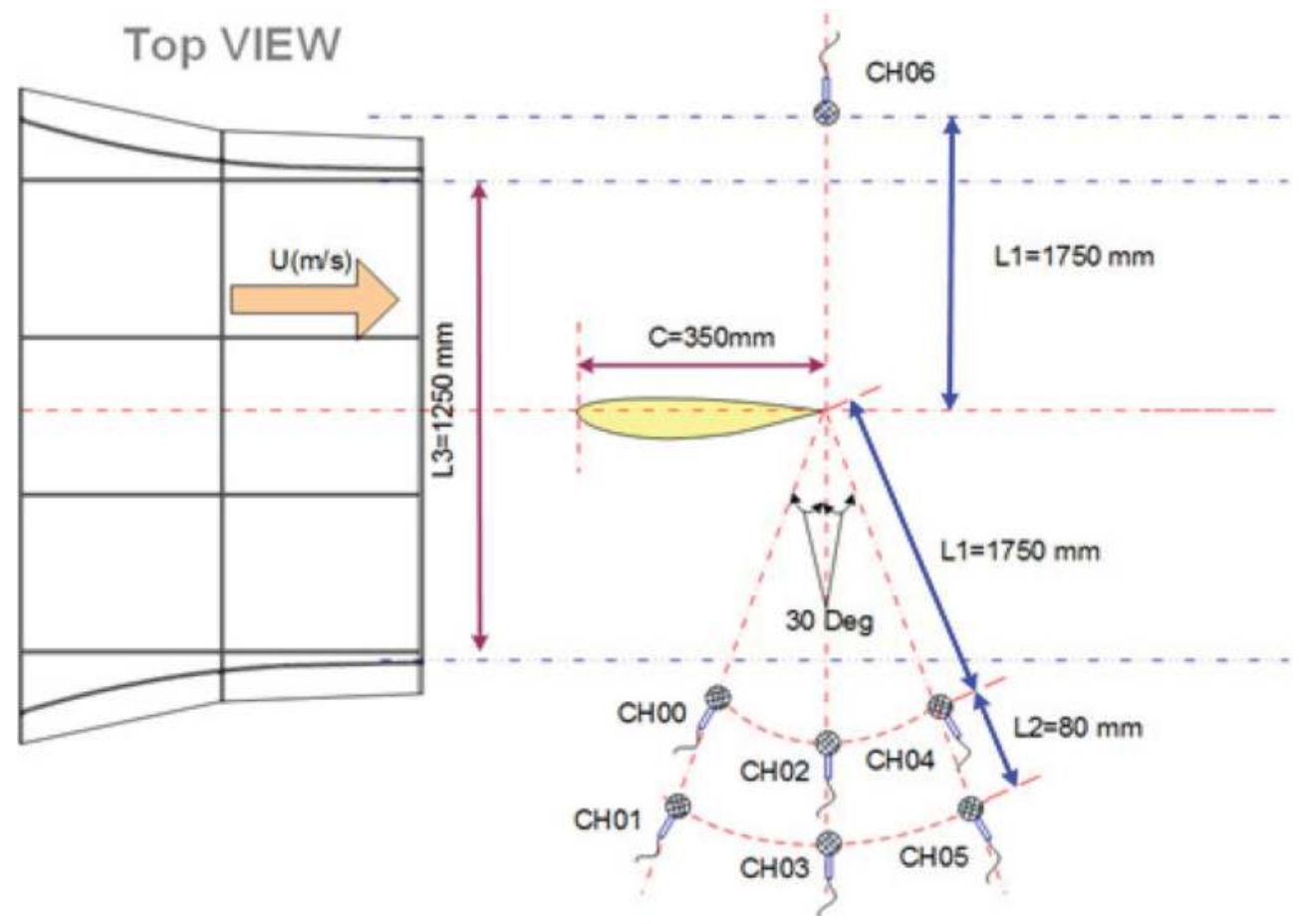

Figure 3. Layout of the microphone array for the 2D airfoil noise test in the open-jet wind tunnel.

and by Garner et al. [12] were applied; tunnel height and chord length were used as major variables in the two calibration methods. The aerodynamics performance experiment results of the 2D airfoil have been introduced by Ryi \& Choi [8].

\subsection{Noise measurement results of $2 \mathrm{D}$ airfoils with trailing edge serrations}

Figure 6 shows the differences in noise levels between a 2D airfoil with a rectangular plateshape trailing edge and a 2D airfoil with serrated trailing edges. A noise value greater than zero indicates the presence of a noise reduction effect. A noise value smaller than zero indicates the absence of a noise reduction effect. It was observed that the noise effect increased with an increase in the angle of attack, and the maximum noise reduction reached about $3 \mathrm{~dB}$.

These experimental results confirmed that the use of serrated trailing edges can improve aerodynamic performance and noise performance. This study intended to confirm the noise reduction effect of serrated trailing edges by applying trailing edge serrations to an existing rotor system. 


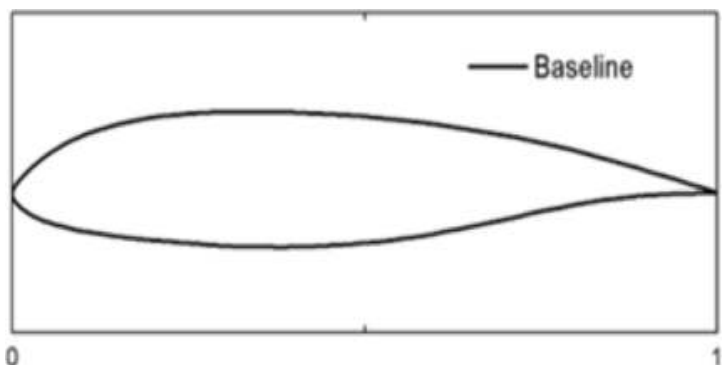

0

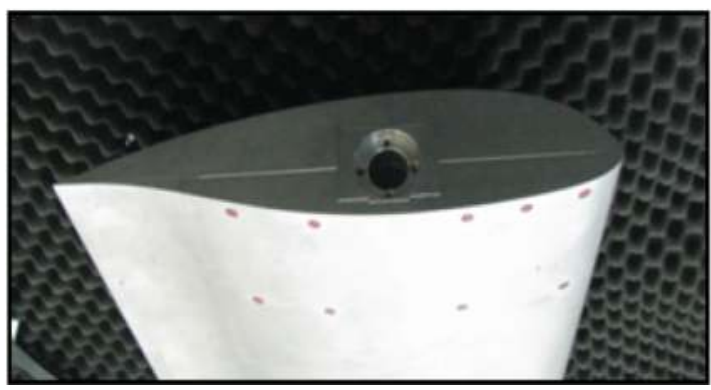

Figure 4. Baseline airfoil test model [10].

$$
L_{\text {differance }}(d B)=L_{\text {baseline }}(d B)-L_{\text {serrated } T E E}(d B)
$$

As seen in Eq. (3), the study compared differences in noise between the plane-shaped trailing edge and the serrated trailing edge within the same frequency domain. As seen in Figure 7, the results confirmed a noise reduction effect in the frequency range of about $500 \mathrm{~Hz}-20 \mathrm{kHz}$.

\subsection{Experiment on wake characteristics of 2D airfoils with serrated trailing edges}

If a serrated trailing edge is attached to a 2D airfoil, a noise reduction effect is produced. However, in such a case, the basic preconditions suggested by Howe's theory are not satisfied, according to the results of previous experiments. This study assumed that the Howe's precondition amplitude of serrations and the boundary layer thickness of $2 \mathrm{D}$ airfoils are constant, and this is not satisfied. For this reason, the study set up the experimental apparatus to measure the wake of 2D airfoils, as seen in Figure 8, and used a single axis hot-wire anemometer to measure the wake in the $y / C$ direction (span-wise) and in the $\mathrm{z} / \mathrm{C}$ direction (wake-wise) of serrated trailing edges as well as 8 different types of airfoils.

Figure 9 shows the results of the experiments conducted with eight types of airfoils. Because of the shapes of the serrated trailing edges, measurements were taken at $240 \mathrm{~mm}$. In the case of $2 \mathrm{D}$ airfoils with rectangular plate trailing edges, there were no changes in frequency in the span-wise direction depending on the shapes of the serrations, and there were no abnormal phenomena. However, this study assumes distinctive frequency patterns depending on the shapes of serrations and the peak and valley positions. Therefore, the study demonstrated 

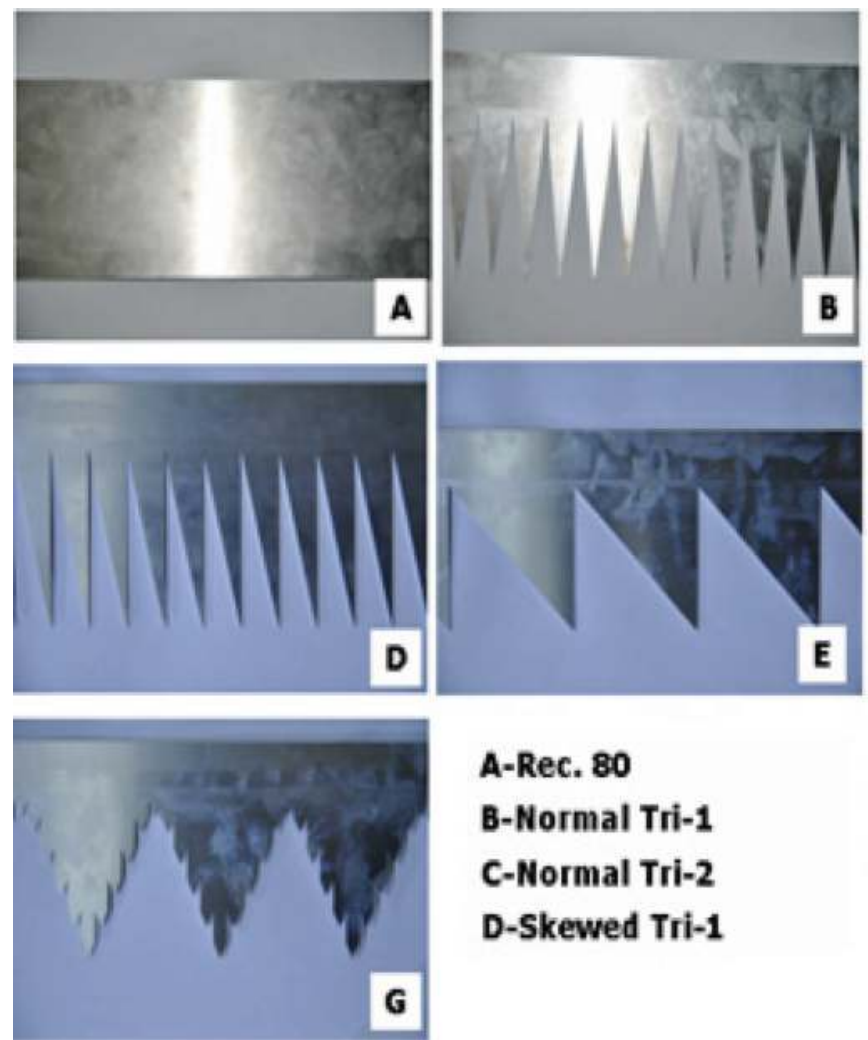

A-Rec. 80

B-Normal Tri-1

C-Normal Tri-2

D-Skewed Tri-1
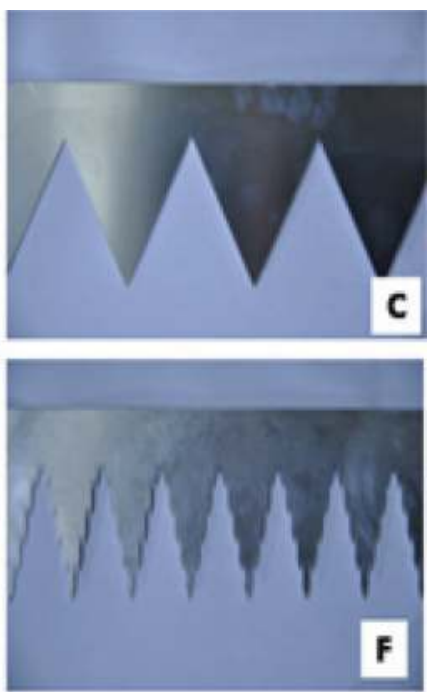

E-Skewed Tri-2

F-Multi. Tri-1

G-Multi. Tri-2

Figure 5. Serration trailing edge test model [10].

\begin{tabular}{lllll}
\hline Serration type & $\lambda / \mathbf{h}$ & $\boldsymbol{\theta}\left(^{\circ}\right)$ & $\lambda_{s}(\mathbf{m m})$ & $\mathbf{2 h}(\mathbf{m m})$ \\
\hline Baseline & N/A & N/A & N/A & N/A \\
Rec80 & N/A & N/A & N/A & N/A \\
Nor. Tri (narrow) & 0.5 & 7.125 & 20 & 80 \\
Nor. Tri (wide) & 2 & 26.565 & 80 & 80 \\
Skew. Tri (narrow) & 0.5 & 14.03 & 20 & 80 \\
Skew. Tri (wide) & 2 & 22.5 & 80 & 80 \\
Multi. Tri (narrow) & 1 & 28.07 & 40 & 80 \\
Multi. Tri (wide) & 2 & 26.565 & 80 & 80 \\
\hline
\end{tabular}

Table 1. Serrated trailing edge configuration. 


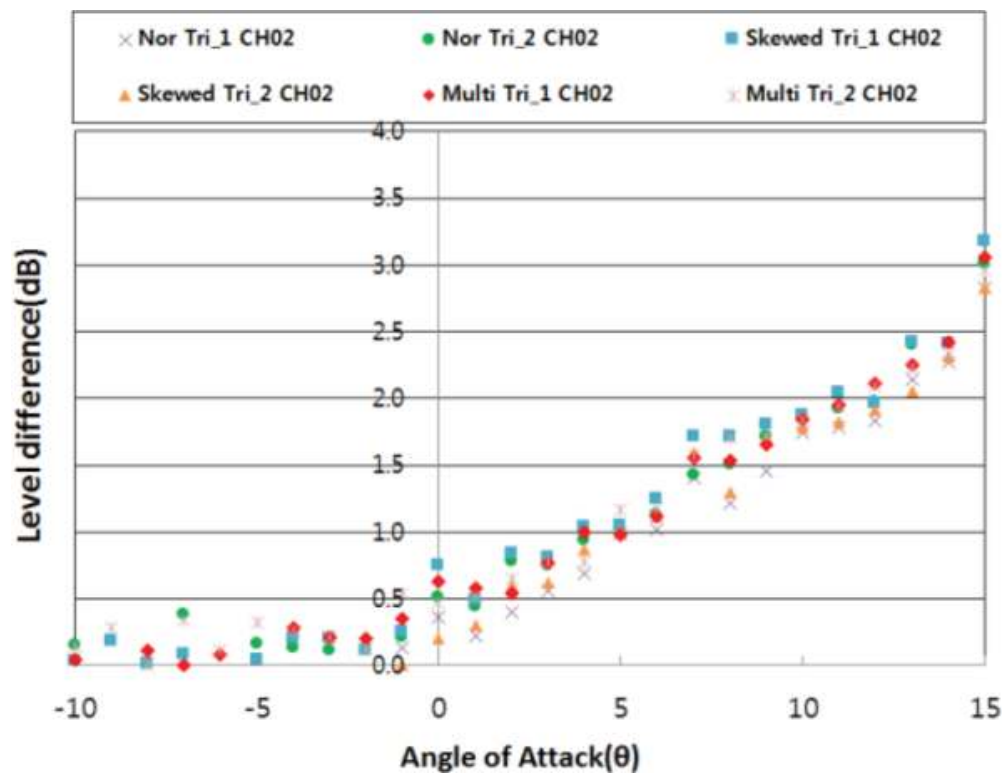

Figure 6. Noise level difference of baseline airfoil with serration trailing edge.

differences in the components of vortex shedding frequency in the wake of the trailing edge when serrated trailing edges were used, under the same operating conditions as for 2D airfoils.

\subsection{Measurement of serrated trailing edge wake (included information)}

The results of the wake measurement of $2 \mathrm{D}$ airfoils with serrated trailing edges in the $\mathrm{y} / \mathrm{C}$ direction revealed that frequency changes occurred depending on the peak and valley positions of the serrated trailing edges. Based on these experimental results, the wake in the $\mathrm{z} / \mathrm{C}$ direction was measured via the mean flow distribution, depending on the locations of the serrated trailing edges in the span-wise direction. Figure $\mathbf{1 0}$ shows a conceptual diagram of the wake measurement experiment in the $\mathrm{z} / \mathrm{C}$ direction using the same experimental devices as for the wake measurement experiment in the $\mathrm{y} / \mathrm{C}$ direction. Figure $\mathbf{1 1}$ gives information about the axial directions of serrated trailing edges and the wake measurement locations. The tip of the serrated trailing edge was defined as the peak, while the inside of the serrated trailing edge was defined as the valley. The wake measurement experiment was conducted by defining the $(x, y, z)$ axes of the tip of the serrated trailing edges as $(0,0,0)$.

Figure 12 shows the results of the wake measurements of six types of serrated trailing edges. When serrated trailing edges were attached, varying wake distributions were observed depending on the types of serrated trailing edges. Boundary layer changes of the $2 \mathrm{D}$ airfoils and different flow distributions in the peak and valley positions were observed. According to these results, the precondition suggested by Howe to explain the noise reduction effect of serrated trailing edges, that all the boundary layer thicknesses are constant, was not satisfied. 


\section{Baseline Airfoil Noise Test}

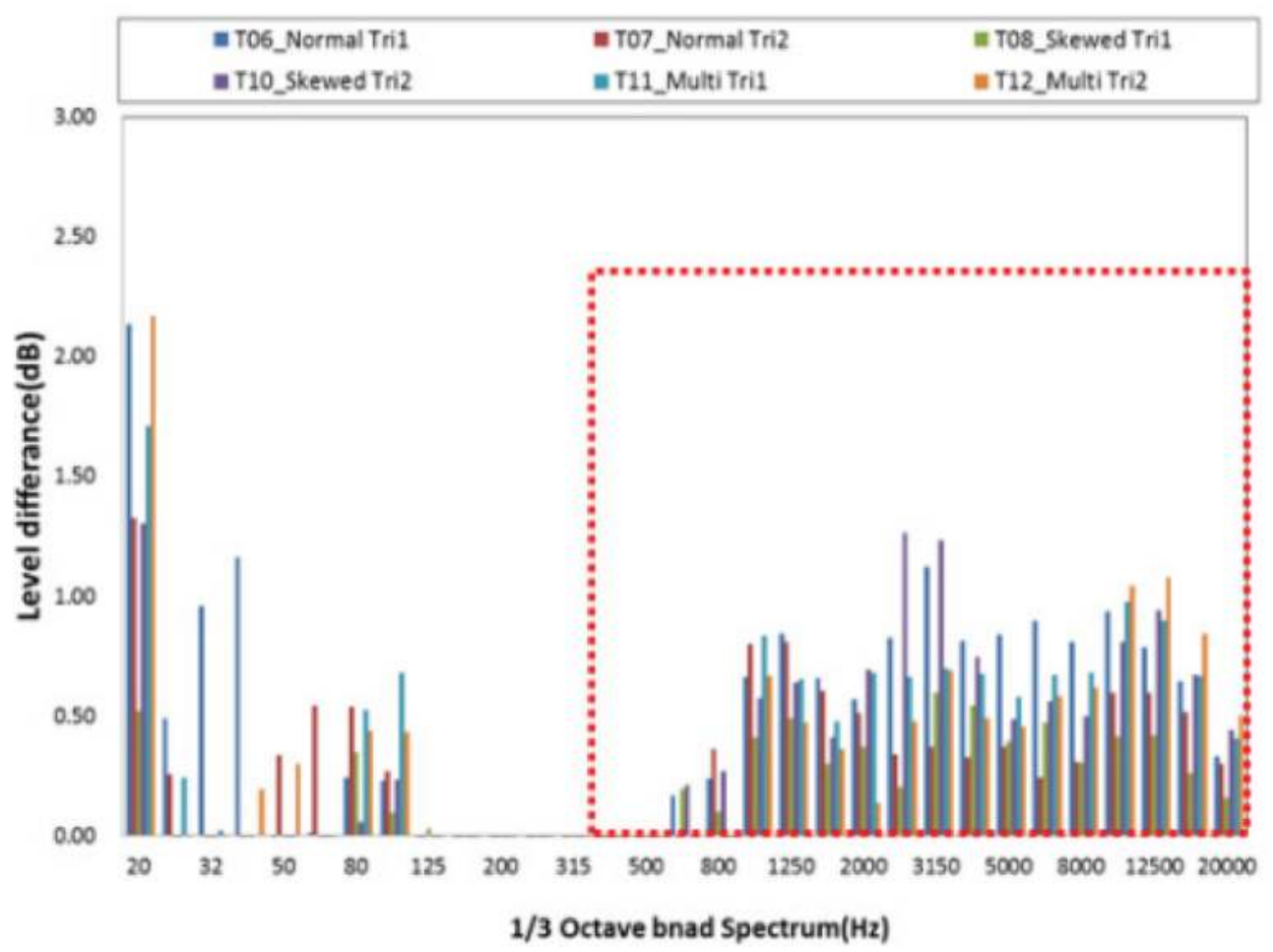

Figure 7. Noise reduced effect for serration trailing edge.

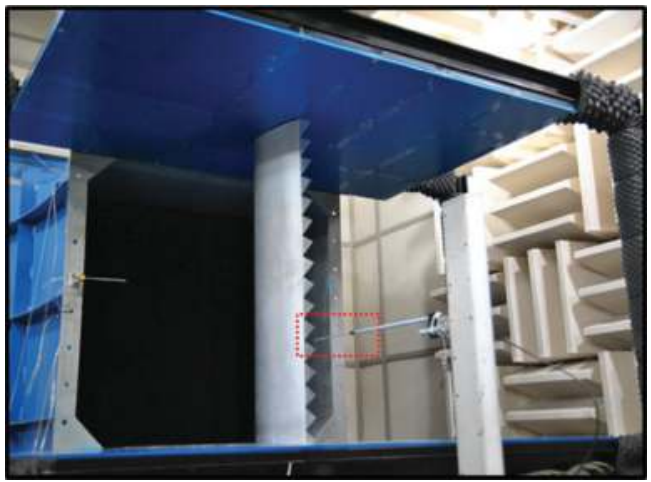

Figure 8. Configuration of wind tunnel test stand for airfoil wake measurement system 

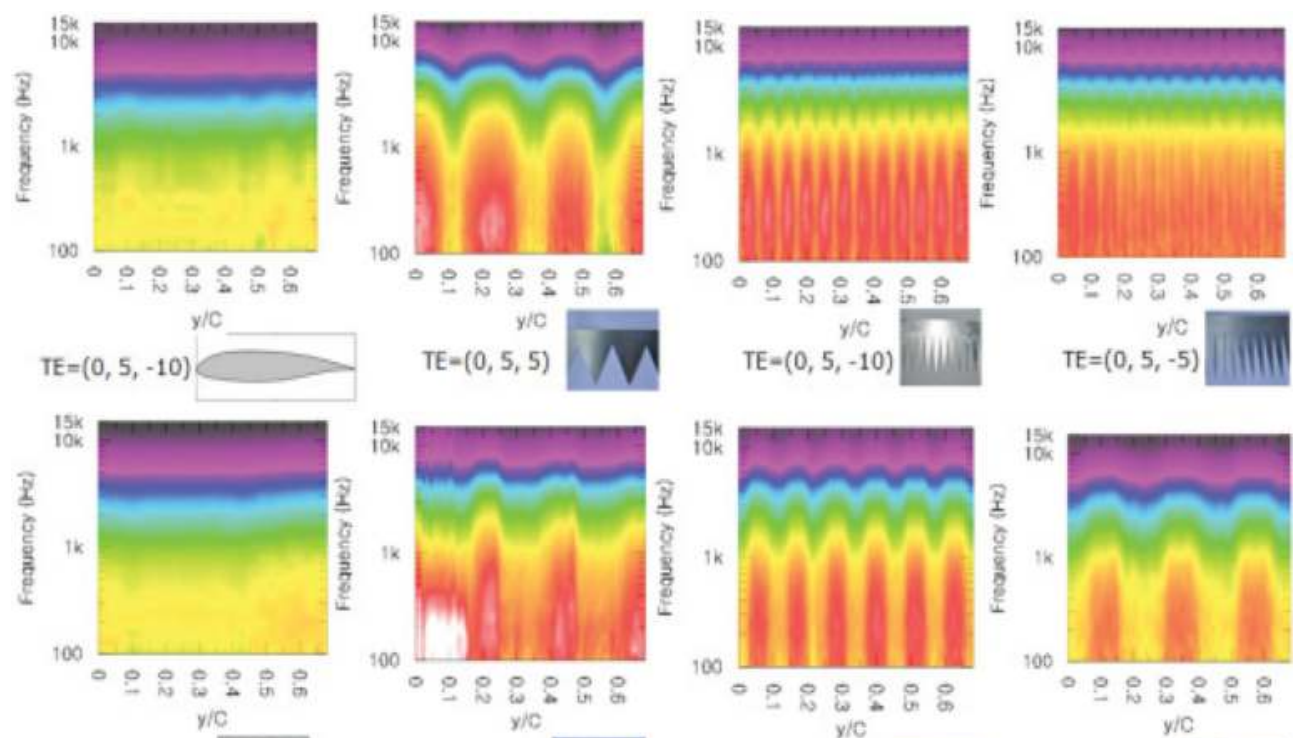

$\mathrm{TE}=(0,5,-10)$

$\mathrm{TE}=(0,5,-10)$

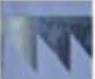

$\mathrm{TE}=(0,5,-10) \quad / 1 / \mid \mathrm{TE}=(0,5,-10)$

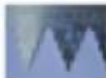

Figure 9. Velocity spectral map for the plate with serrations measured in the span-wise direction: various serration plate.

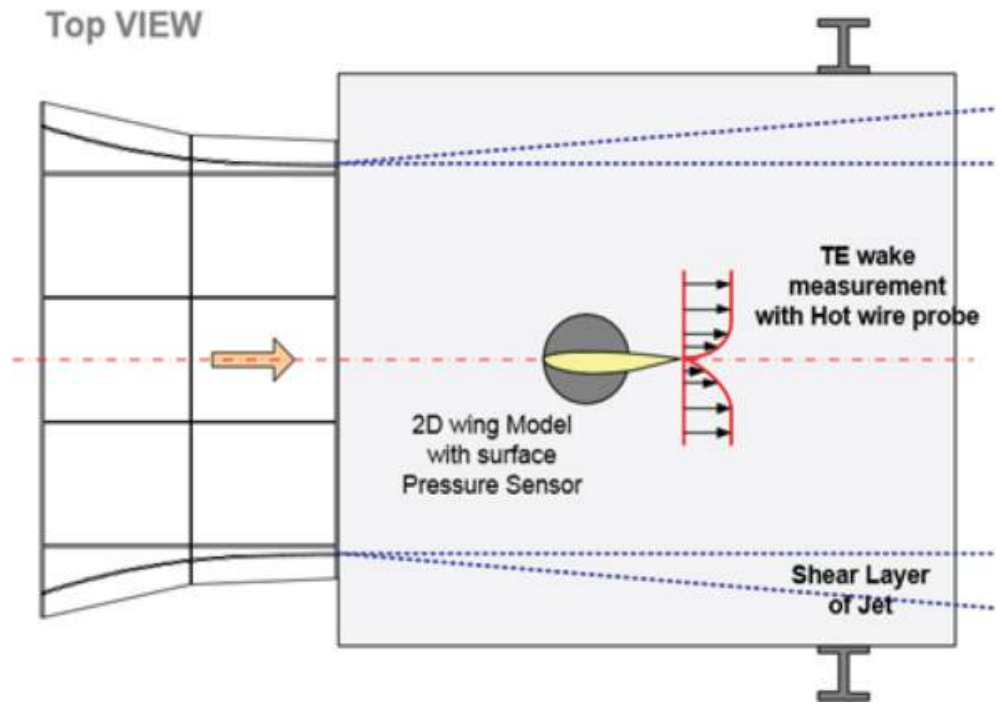

Figure 10. Layout of wake measurement for serration trailing edge in the z-axis direction [8]. 


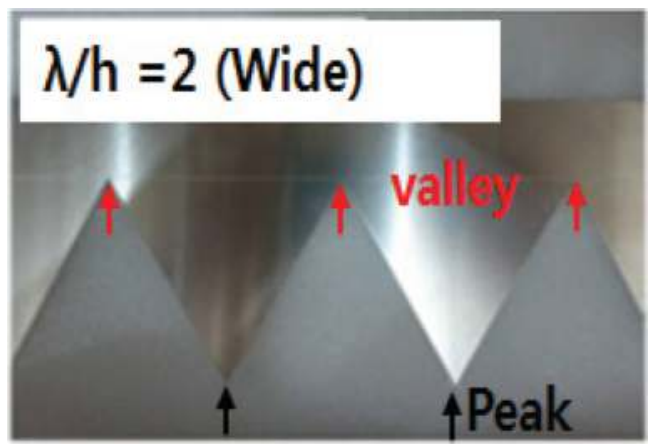

Figure 11. Layout of serration plate [8].

\section{Empirical formula for noise reduction prediction in 2D airfoils with serrated trailing edges}

In this chapter, we confirmed the noise reduction effect induced by serrated trailing edges and identified changes in aerodynamic performance and noise performance. Thus, this study confirmed changes in the frequency components in the wake and the velocity distribution when a serrated trailing edge was attached to a 2D airfoil.

Noise in a 2D airfoil is caused by the boundary layer between the surfaces of the blades, the vortex in the blades, and blade interference. The noise in the wind turbine blade cross-section is defined as self-noise, and different characteristics of self-noise were observed depending on the cross-sectional shape of the blade, flow conditions, and angles of attack. As 2D airfoil selfnoises are usually caused by a combination of multiple factors, it is difficult to identify the exact cause of changes. Brooks et al. [13] suggested an empirical prediction formula based on the results of an aerodynamic noise experiment conducted on an NACA0012 airfoil.

The current study suggests a noise prediction formula for serrated trailing edges using the acoustic model suggested by Brooks, thickness and material for serration strip based on the results of the aerodynamic noise test and the wind tunnel test conducted on serrated trailing edges [14].

$$
S P L_{\text {Total }}=S P L_{\text {TBLTE }}-S P L_{\text {serration } T: E}
$$

The 2D airfoil noises which occur in the wind tunnel test are often heavily influenced by turbulent boundary layers. Based on this fact, Eq. (4) was designed to exclude those noise components which can be altered by serrated trailing edges. Figure 13 presents information on the noise components of 2D airfoils with serrated trailing edges.

Figure 14 shows the "Bell-Type" function for serration trailing edge about Frequency Domain. As seen in Eqs. (5)-(10), the results confirmed noise reduction effect for various aspect ratios of serrations trailing edge [10] (Figure 14). 
(a)

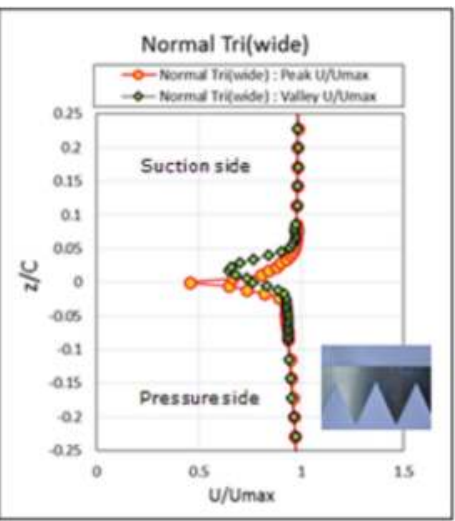

(b)

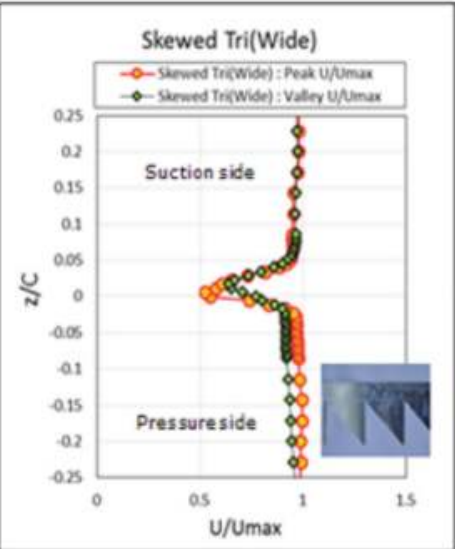

(c)

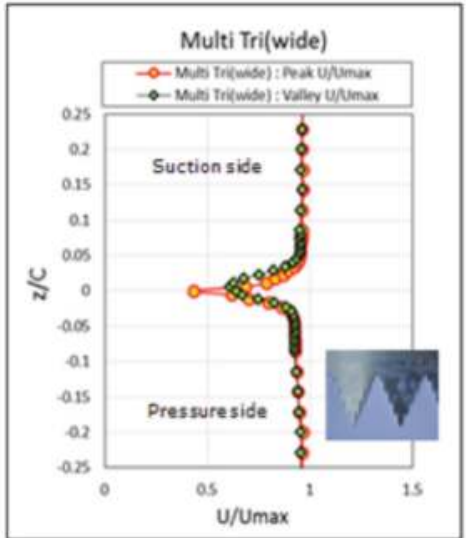

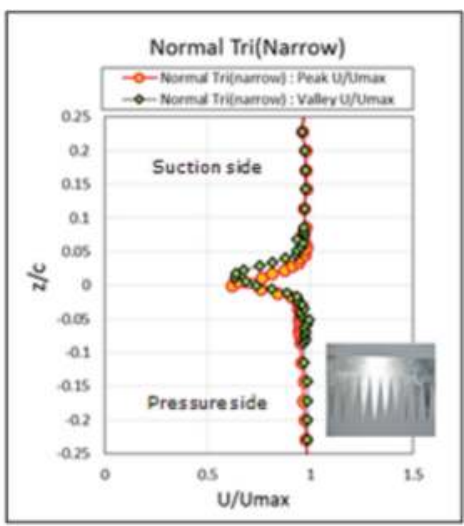
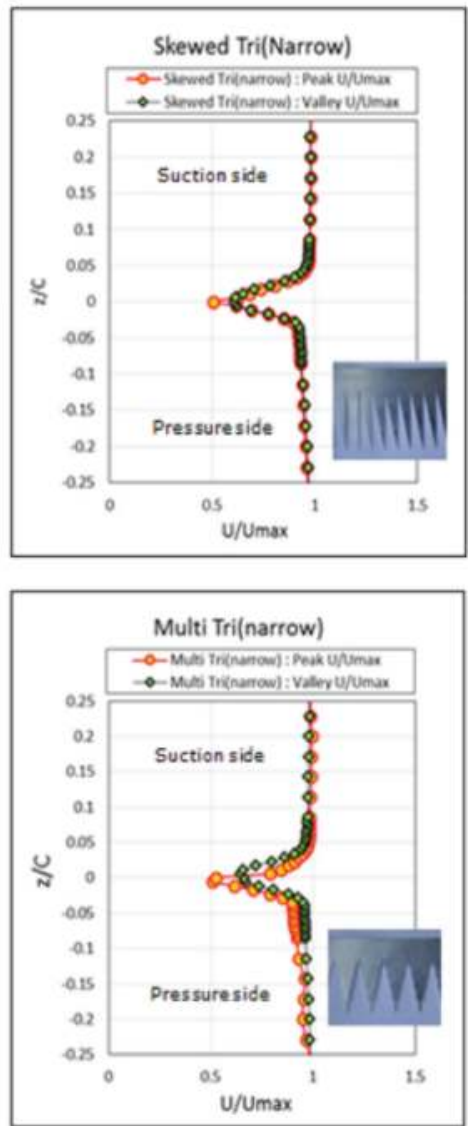

Figure 12. Mean velocity distribution for the plate with different serrations measured in the $\mathrm{z}$ axis direction [8]. (a) Nor-mal-type serrations; (b) skewed type serrations; (c) multi-type serrations. 
- $\quad$ The predicted sound field spectrum [10]

$$
S(f) \approx \frac{1}{8 \pi^{2} R^{2}}\left(\frac{U_{c} L}{c_{0}}\right) l_{y}(f) \Phi(f)
$$

- Oscillatory function of trailing edge

$$
l_{\nu}(f)=\frac{U_{c}}{\varepsilon 2 \pi f}
$$

- $\quad$ Surface pressure Term: Frequency domain

$$
\Phi(f)=\frac{\Phi\left(S t^{*}\right) l q^{2}}{U_{\max }}
$$

- Strouhal number function

$$
S t^{*}=\frac{f L(x)}{U_{\max }}
$$

- Span-wise length scale function

$$
L(x)=\left[\log g\left(\frac{\lambda_{s}}{h}\right)^{0.015}+0.12\right]^{2}
$$

- Estimation function for serration trailing edge noise reduction effect

$S P L_{\text {serration T.E. }}$

$$
\begin{gathered}
=3.5-8\left[\log \left(S t^{*}\right)+0.3\right]^{2}-\left[\log \left(\frac{\lambda_{s}}{h}\right)+0.4\right]^{2} \\
\therefore S P L_{\text {serration } T . E \text {. }} \geq 0
\end{gathered}
$$

\subsection{Verification of performance of NACA0012 airfoil}

The empirical formula for prediction of 2D airfoil self-noises by Brooks was developed based on the results of an experiment conducted on an NACA0012 airfoil. If an airfoil with a camber or a serrated trailing edge is used, it is impossible to directly apply the prediction model suggested by Brooks, because there can be changes not in the blade of a symmetric airfoil but in aerodynamic performance. To predict noise under such conditions, the lift slope was calibrated to the baseline lift coefficient. Figure 15 gives information about the NACA0012 airfoil with a serrated trailing edge in the wind tunnel test. 


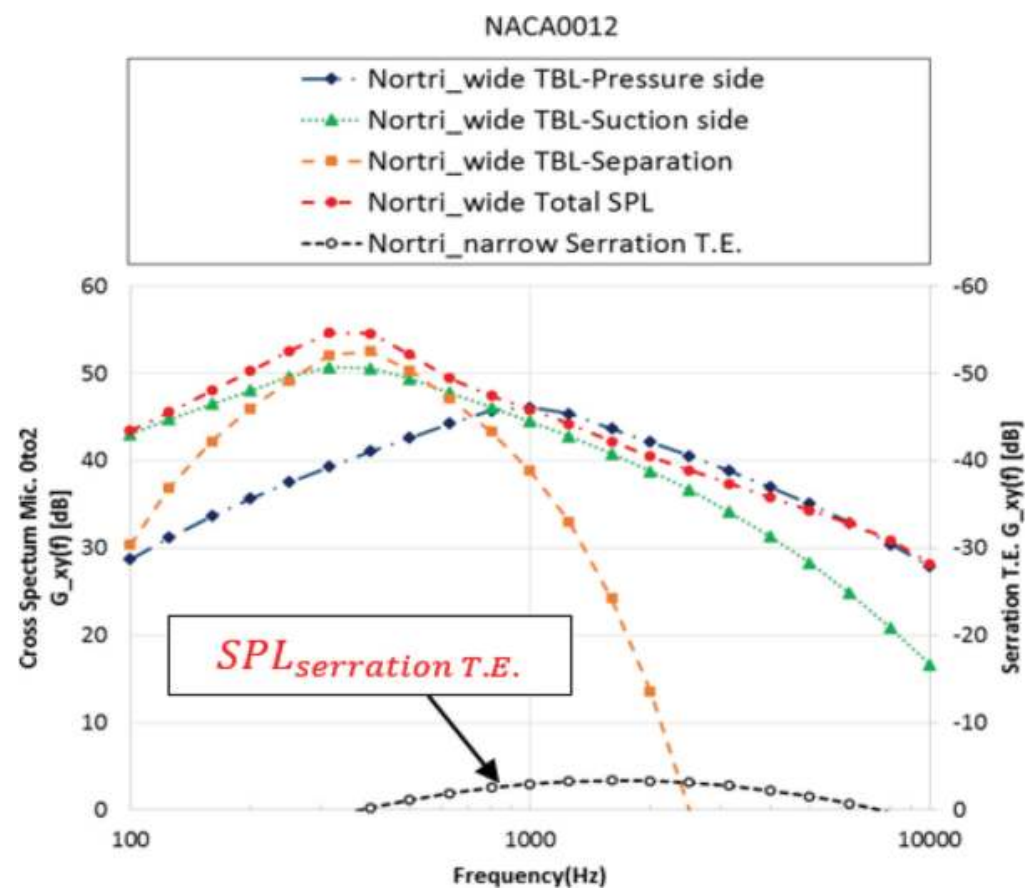

Figure 13. Estimation of serration trailing edge noise.

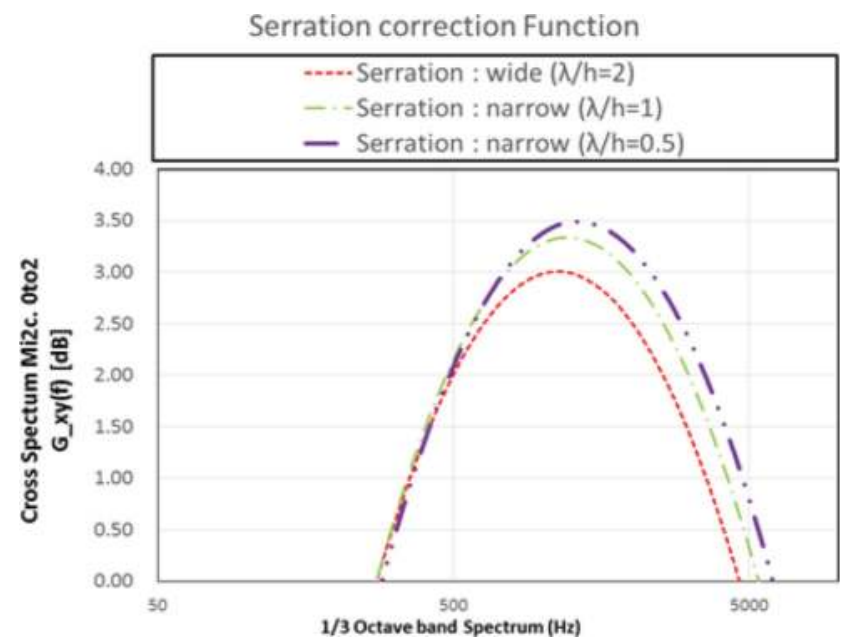

Figure 14. Bell function for serration trailing edge about frequency domain.

To analyze the noise prediction performance of the NACA0012 airfoil, an experiment was conducted under the conditions given in Table 2, and the results were used for a comparative analysis. A comparative analysis of the differences between the experimental results and the 


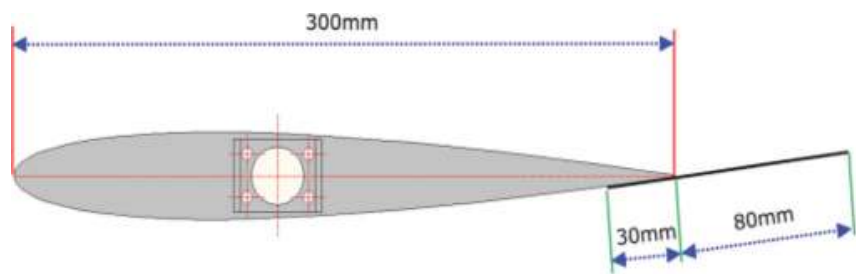

Figure 15. NACA0012 airfoil with serration trailing edge.

\begin{tabular}{llll}
\hline Model & Lift coefficient & AOA $^{*}$ & Remark \\
\hline NACA0012 & 0.50 & 5.03 & N/A \\
Serration narrow & 0.43 & 4.43 & $\lambda / \mathrm{h}=0.5$ \\
Serration wide & 0.42 & 4.40 & $\lambda / \mathrm{h}=2$ \\
\hline
\end{tabular}

Wind speed $=30 \mathrm{~m} / \mathrm{s}$.

Table 2. NACA0012 airfoil test condition.

predicted results was carried out under a total of three conditions (one, a 2D airfoil without a serrated trailing edge; and, two and three, the narrow and wide conditions of a normal tri-shaped

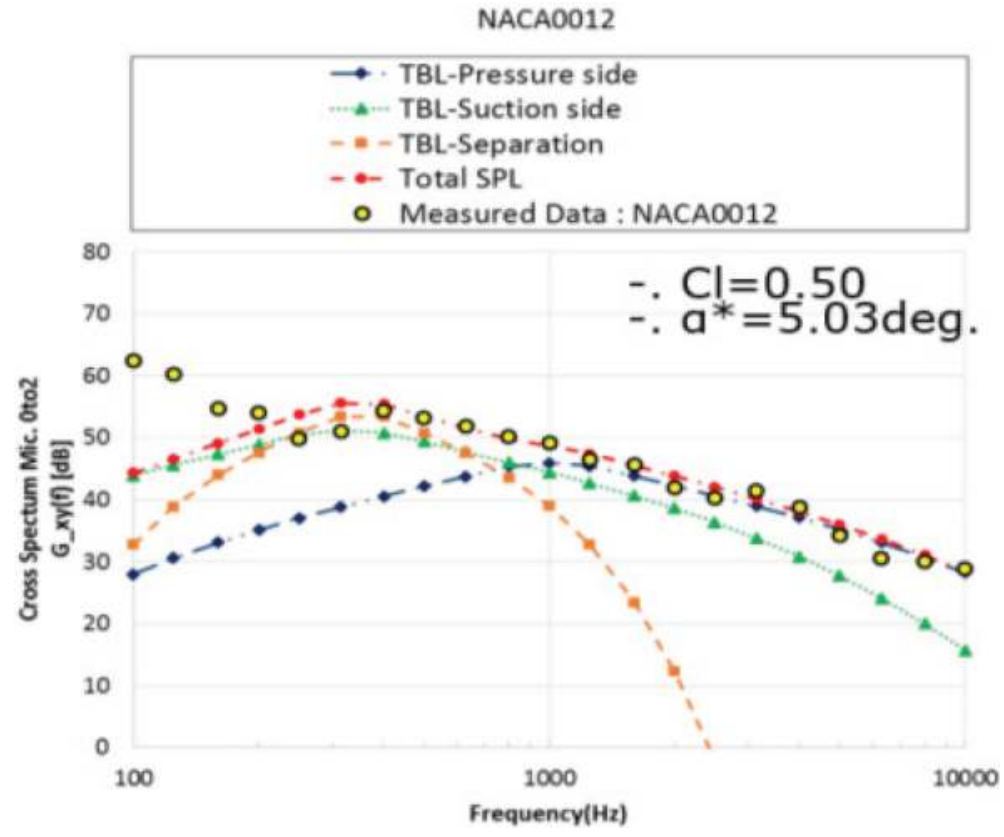

Figure 16. The wind tunnel test and estimation for NACA0012 airfoil condition. 
airfoil with a serrated trailing edge). The measurement of noises collected through the microphones was used to calculate the cross spectrum between $\mathrm{CHO0}$ and $\mathrm{CH} 02$, utilizing a noise prediction program which was developed based on the empirical formula suggested by Brooks et al. [13].

Figure 16 shows the results of comparative analysis of the noise prediction values of the NACA0012 airfoil with the actual measured values. The measured values are consistent with the predicted values. Differences in the low frequency domain ( $300 \mathrm{~Hz}$ or below) can be ascribed to the background noise of the anechoic wind tunnel test facility.

As seen in Figure 17, the noise reduction effect produced by a serrated trailing edge was analyzed by applying the contents of the noise prediction formula for the NACA0012 airfoil and the empirical formula suggested by Brooks et al. [13] for prediction of noises in the serrated trailing edge, as seen in Eqs. (5)-(10). After conducting an experiment under the narrow condition, the predicted values were compared with the experimental values. According to the prediction, noises ranging from $500 \mathrm{~Hz}$ to $10 \mathrm{kHz}$ should be reduced by the inclusion of a serrated trailing edge. Figures $\mathbf{1 7}$ and $\mathbf{1 8}$ shows the results of the experiment conducted under the wide condition, as well as the results of the comparative analysis of the predicted values and the measured values. In accordance with the prediction, it was found that noises ranging from $300 \mathrm{~Hz}$ to $8 \mathrm{kHz}$ were reduced (Figure 18).

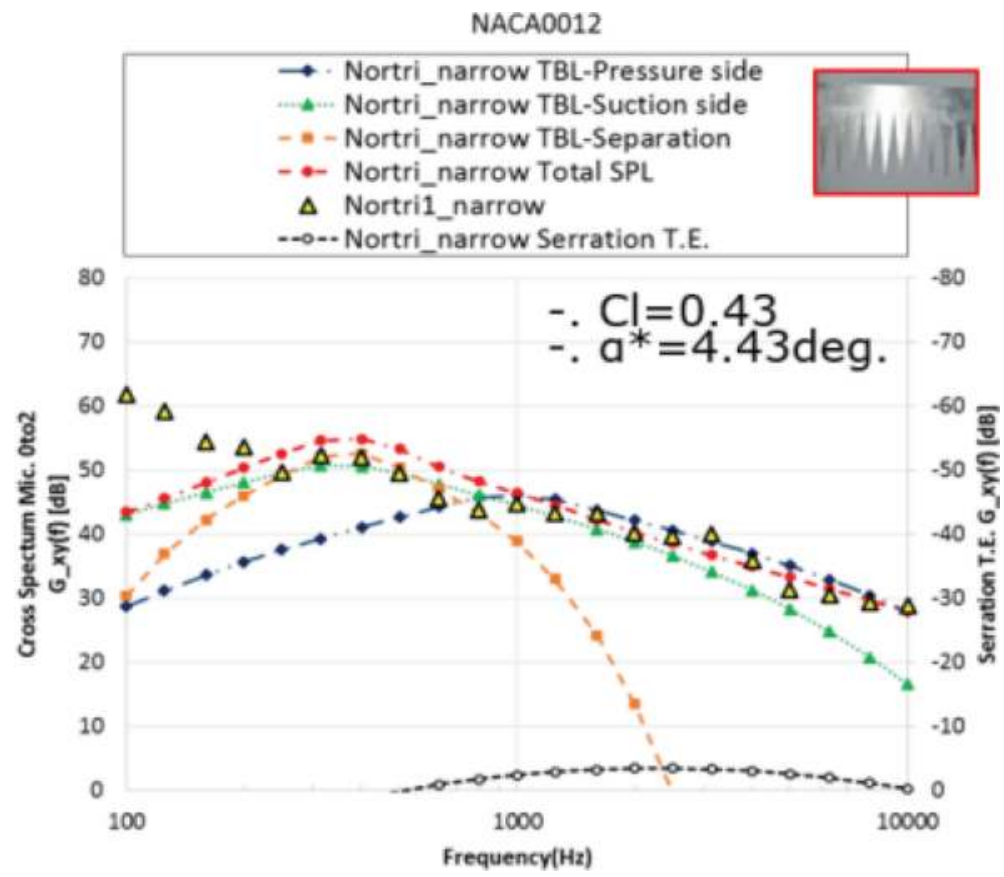

Figure 17. The wind tunnel test and estimation for NACA0012 with narrow serration plate. 


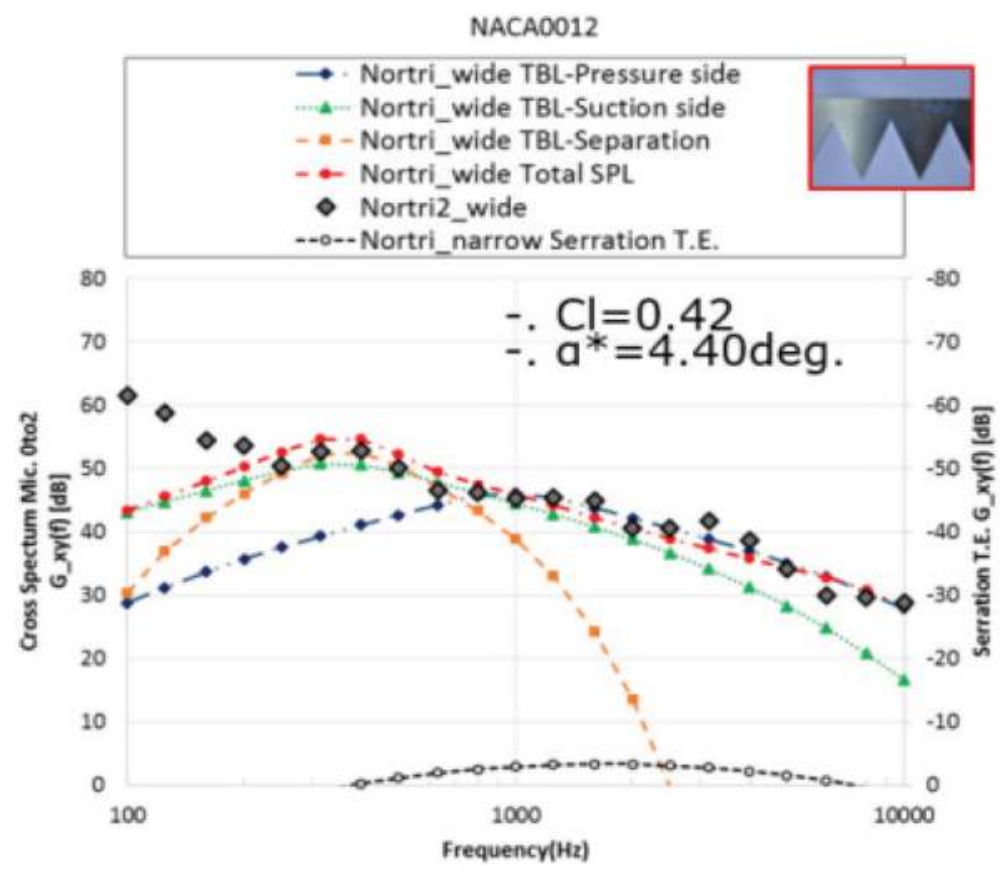

Figure 18. The wind tunnel test and estimation for NACA0012 with wide serration plate.

\subsection{Verification of baseline airfoil performance}

In this study, using the NACA0012 airfoil, experimentally tested Brooks' noise prediction formula and the noise prediction equation for the serrated tail edge are proposed. The prediction of noise reduction in the baseline airfoil with the shape seen in Figure 19 was conducted, and the predicted results were compared with the experimentally obtained values. Based on the results of the wind tunnel test, the lift slope was calibrated to the baseline lift coefficient in order to predict airfoil self-noises.

For the analysis of noise prediction of the baseline airfoil, an experiment was conducted under the conditions given in Table 3, and the measured results were compared with the predicted results. For a comparative analysis between the predicted values and the experimentally obtained values, the experiment was conducted under a total of three conditions, the single

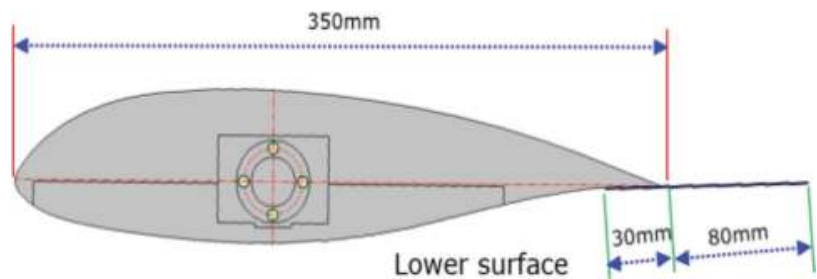

Figure 19. Baseline airfoil with serration trailing edge. 


\begin{tabular}{llll}
\hline Model & Lift coefficient & AOA* & Remark \\
\hline Baseline & 0.59 & 4.60 & N/A \\
Serration narrow & 0.51 & 4.48 & $\lambda / \mathrm{h}=0.5$ \\
Serration wide & 0.55 & 4.49 & $\lambda / \mathrm{h}=2$ \\
\hline
\end{tabular}

Wind speed $=30 \mathrm{~m} / \mathrm{s}$.

Table 3. Baseline airfoil test condition.

condition of a 2D airfoil without a serrated trailing edge, and the narrow condition and wide conditions of the normal tri-shaped airfoil with a serrated trailing edge, as was done with the NACA0012 airfoil. The noises collected through the microphones were used to calculate the cross-spectrum between $\mathrm{CH} 0$ and $\mathrm{CH} 2$, and a noise prediction program which was developed based on the empirical formula suggested by Brooks et al. [13] was utilized to predict 2D airfoil self-noises, as for the NACA0012 airfoil.

Figure 20 shows the results of the comparison between the predicted values of the baseline airfoil and the measured values. It was revealed that the disparities between the measured values of the baseline airfoil and the predicted values were wider than those between the measured and predicted values of the NACA0012 airfoil. Figures 21 and 22 show the predicted results when a serrated trailing edge was applied to a $2 \mathrm{D}$ airfoil. As there were larger

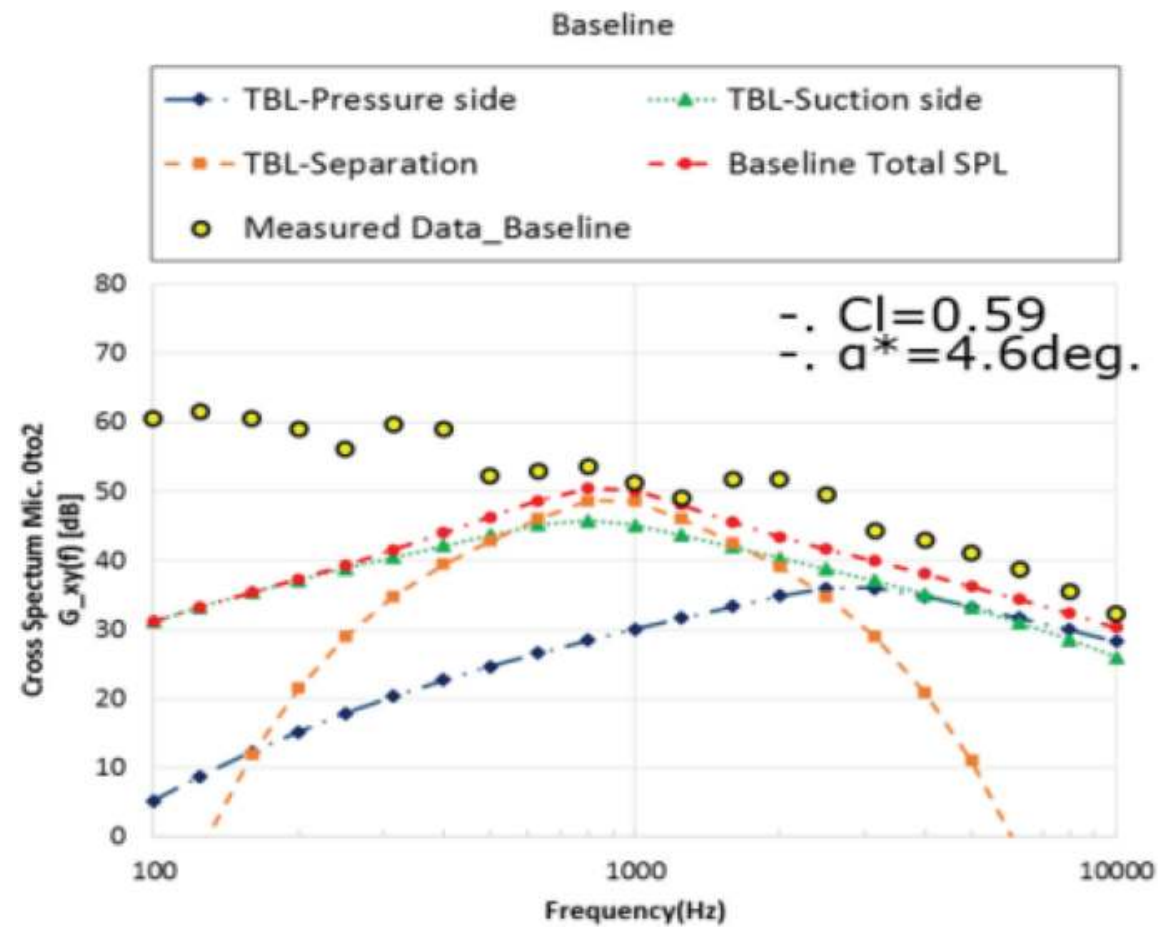

Figure 20. The wind tunnel test and estimation for baseline airfoil condition. 


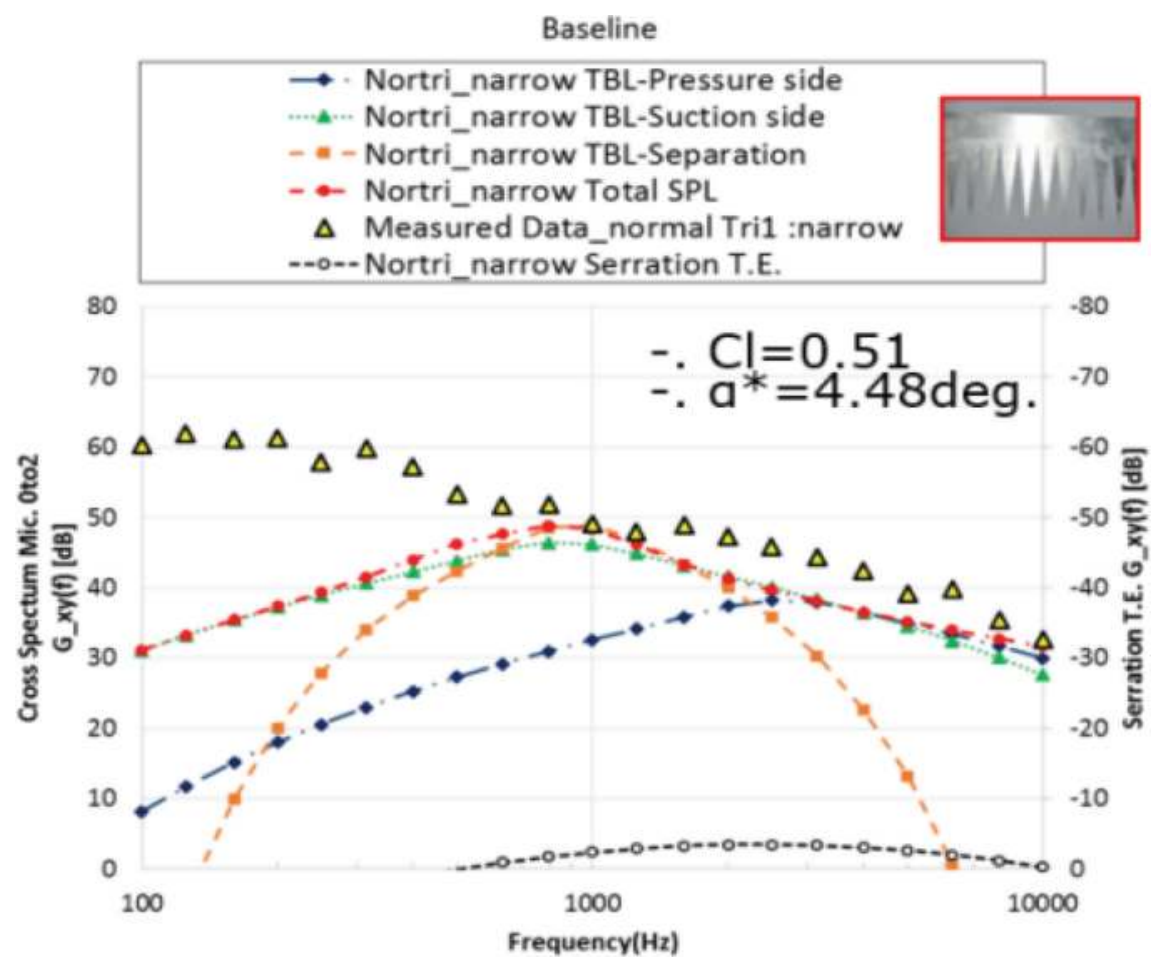

Figure 21. The wind tunnel test and estimation for baseline airfoil with wide serration plate condition.

differences between the predicted values and the measured values in comparison to those of the NACA0012 airfoil, the study showed a similar performance prediction ability under the conditions of interest.

When a serrated trailing edge was applied, noise reduction effects were observed both in the experimental results and the predicted results obtained by the empirical formula, under the same angles of attack. Also, they showed a similar frequency range where noises were reduced. However, it was found that the predicted values were smaller than the experimental values.

\subsection{Review of noise reduction effects of 2D airfoils with serrated trailing edges}

This study examined the noise reduction effects between the NACA0012 airfoil and the baseline airfoil used by a wind turbine rotor, which is considered a standard airfoil, following the application of serrated trailing edges. In this study, the validity of the noise reduction effect was confirmed under the angle of attack set as a precondition. This study utilized Brooks' empirical formula for noise reduction in 2D airfoils and the 'Bell-type' noise prediction empirical formula in order to examine the noise reduction effect of serrated trailing edges. As mentioned in 


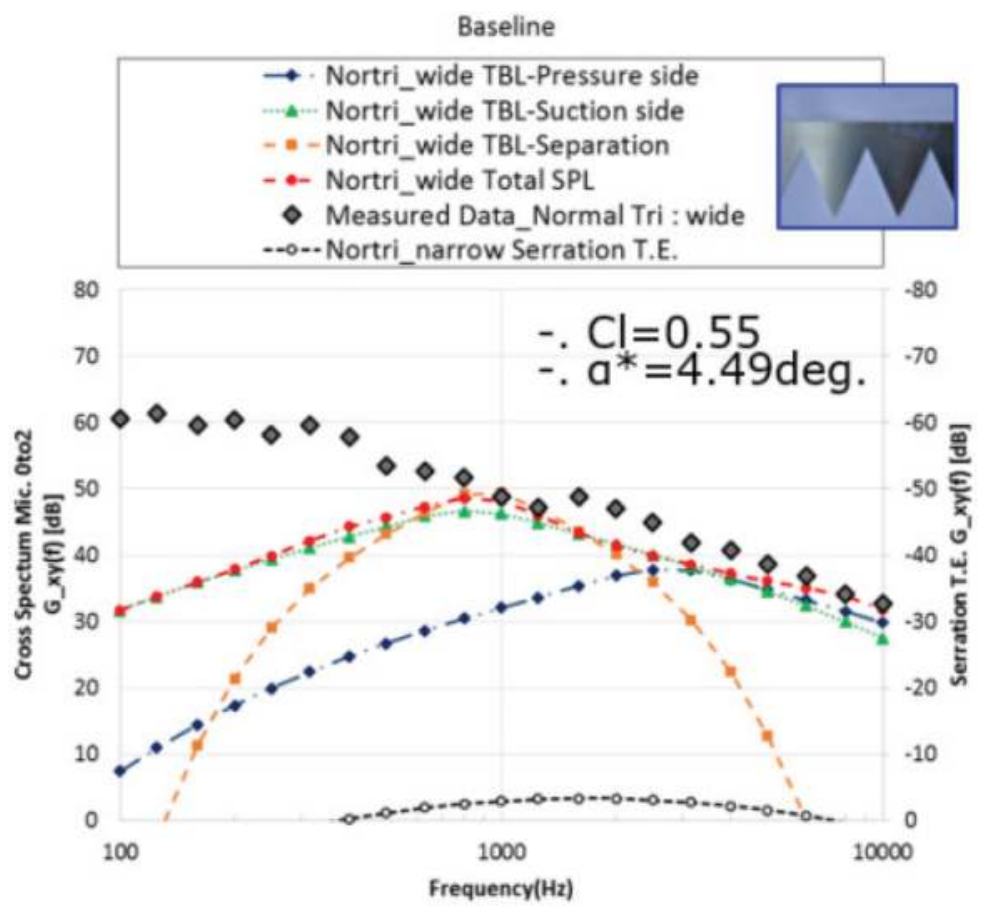

Figure 22. The wind tunnel test and estimation for baseline airfoil with wide serration plate condition.

the beginning of Section 4, however, this study has certain limitations, such as the range of noise experiment results and the limited types of $2 \mathrm{D}$ airfoils.

There were differences in the installation angles of serrated trailing edges depending on the shapes of the 2D airfoils, which may have caused variations in the frequency ranges of noise reduction, even when the same serrated trailing edge was used. Such an effect was noted in previous studies conducted from 1997 to 1999 in the JOULE-III program in Europe to measure the noises generated by a wind turbine rotor [12]. If follow-up studies take this effect into account, it may be possible to propose a more accurate noise prediction empirical formula than the one reviewed by this study.

Another limitation is related to the prediction formula defined as "Bell-type" by this study. This study conducted a 2D wind tunnel test on the noise reduction effect induced by serrated trailing edges, based on the baseline 2D airfoil used in actual wind turbine rotors. The contents of Figure 23 show the noise reduction prediction function of serrated trailing edges (SPL serration T.E.) and the differences in the noise reduction prediction results between the previously conducted baseline airfoil and the serrated airfoil. The results confirmed that the noise reduction effect appeared as 'Bell-type' in various aspect ratios $(\lambda / h)$ of serrated trailing edges. 


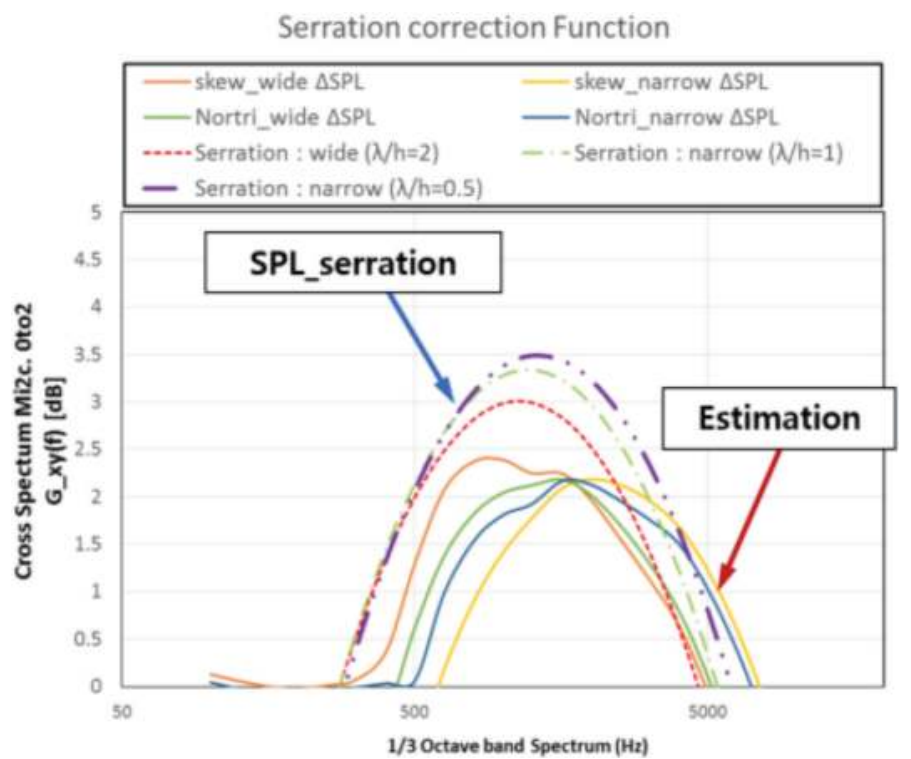

Figure 23. Cross spectrum of baseline airfoil with serration trailing edge.

\section{Comparison of level differance}

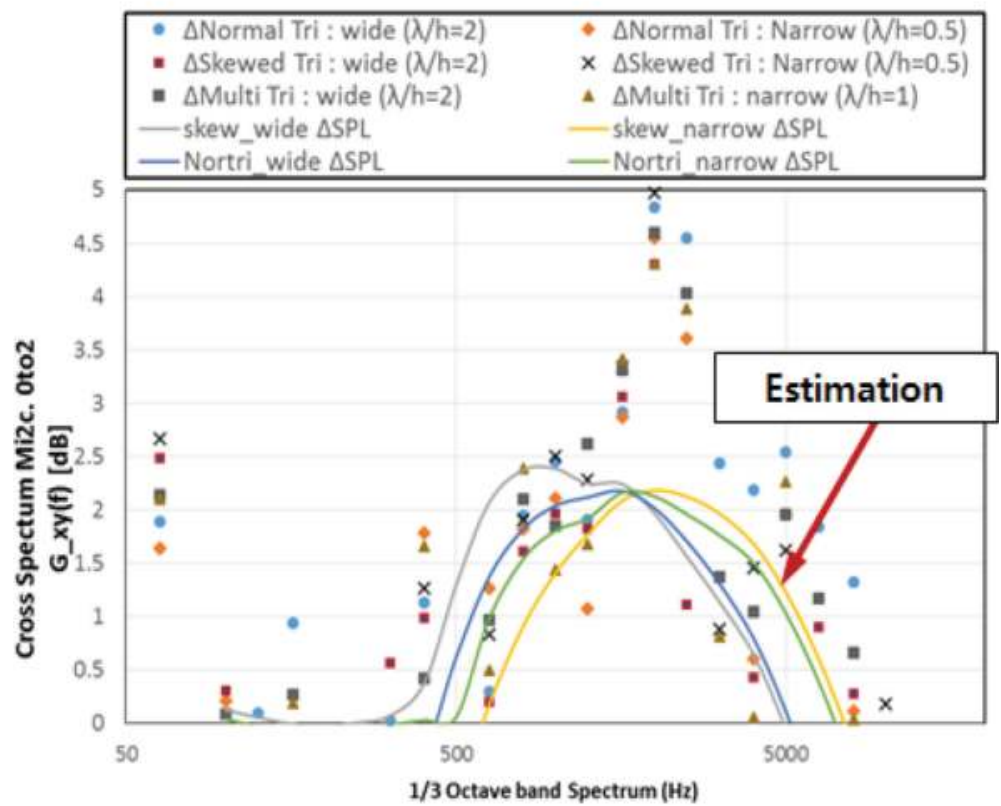

Figure 24. The level difference of baseline airfoil with serration trailing edge. 
Figure 24 shows both the predicted results and the experimental results of the noise reduction effect induced by serrated trailing edges. The experimental results showed a 'Bell-type' distribution, but in some conditions, the distribution was more similar to 'Cone-type'. If further experiments are conducted based on the shape of serrated trailing edges, apart from the experimental conditions used in this study, it may be possible to improve the accuracy of the noise prediction formula.

\section{Conclusion}

A wind tunnel experiment was conducted on 2D airfoils, and the noise reduction effect was examined based on aerodynamic performance. Using the wind tunnel test on 2D airfoils with serrated trailing edges, wake distribution measurements and an analysis of their relationship with acoustic characteristics were conducted in order to examine the restrictive conditions of Howe's theory. These experimental results confirmed that as changes occur in the boundary layer thickness of 2D airfoils, an empirical formula or a theoretical approach which can reflect these changes is necessary. This study suggested an empirical formula for the prediction of noises in serrated trailing edges by utilizing the wind tunnel results on 2D airfoils with serrated trailing edges, based on the acoustic model suggested by Brooks. Also, the wind tunnel test results and noise prediction results of the NACA0012 airfoil with serrated trailing edges were compared with those of the baseline airfoil, and, through this comparative analysis, the study suggested a new noise prediction empirical formula for $2 \mathrm{D}$ airfoils. The study confirmed the validity of the proposed noise prediction formula by carrying out aerodynamic performance testing and noise measurements on the NACA0012 airfoil, the baseline airfoil, and the serrated trailing edges. However, as the noise prediction formula for the serrated trailing edges was an empirical formula that was based on limited experimental conditions, errors may have arose because of factors including the installation angles of the serrated trailing edges and the cross-sectional shapes of the 2D blades. To make up for the shortcomings in the test results, additional wind tunnel tests need to be conducted, and in consideration of the test results, further studies need to be conducted on the formation of a more accurate noise prediction formula.

\section{Acknowledgements}

This work was supported by research fund of 2014 Chungnam National University of the Korea.

\section{Nomenclature}

$\mathrm{U}$ velocity of the free stream $(\mathrm{m} / \mathrm{s})$

$\lambda s \quad$ span-wise wavelength $(\mathrm{mm})$

h amplitude of serrations (mm) 
$\omega \quad$ acoustic frequency $(\mathrm{Hz})$

SPL sound pressure level, $d B$ re $20 \mu P a$

\section{Author details}

Jaeha Ryi* and Jong-Soo Choi

*Address all correspondence to: bass83@cnu.ac.kr

Department of Aerospace Engineering, Chungnam National University, Daejeon, Korea

\section{References}

[1] Howe MS. Noise produced by a sawtooth trailing edge. Journal of Acoustical Society of America. 1991;90(1)

[2] Braun KA. Serrated trailing edge noise (STENO). In: 1999 European Wind Energy Conference, Nice, France; 1-5 March 1999. pp. 180-183

[3] Gruber M, Joseph PF. Experimental investigation of airfoil self noise and turbulent wake reduction by the use of trailing edge serrations. In: P16th AIAA/CEAS Aeroacoustics Conference, AIAA 2010-3803. 2010

[4] Oerlemans S, Fisher M, Maeder T, Kögler K. Reduction of wind turbine noise using optimized airfoils and trailing-edge serrations. National Aerospace Laboratory, NLR-TP2009-401. 2009

[5] Chong TP, Vathylakis A, Joseph PF, Gruber M. Self-noise produced by an airfoil with nonflat plate trailing-edge serrations. AIAA Journal. 2013;51(11):2665-2677

[6] Finez A, Jondeau E, Roger M. Broadband noise reduction with trailing edge brushes. In: 16th AIAA/CEAS Aeroacoustics Conference, AIAA 2010-3980. 2010

[7] Leung DYC, Yang Y. Wind energy development and its environmental impact: A review. Renewable and Sustainable Energy Reviews. 2012;16:1031-1039

[8] Ryi J, Choi J-S. Noise reduction effect of airfoil and small-scale rotor using serration trailing edge in a wind tunnel test. Science China Technological Sciences. February 2017; 60(2):325-332. ISSN: 1674-7321

[9] Ryi J, Choi J-S, Lee S, Lee S. A full scale prediction method for wind turbine rotor noise by using wind tunnel test data. Renewable Energy. May 2014;65:257-264. ISSN: 0960-1481

[10] Ryi J. Estimation method to achieve a noise reduction effect and to evaluate the aerodynamic performance of a wind turbine rotor with a serrated trailing edge in a wind tunnel 
test [the Degree of Ph.D.]. Department of Aerospace Engineering, Chungnam National University; Feb. 2015

[11] Brooks TF, Marcolini MA. Airfoil trailing edge flow measurements and comparisøn with theory incorporating open wind tunnel corrections. In: AIAA-84-2266, AIAA/NASA 9th Aeroacoustic Conference; 1984

[12] Garner HC, Rogers EWE, Acum WEA, Maskell EC. Subsonic Wind Tunnel Wall Corrections. NATO, AGARD; 1966

[13] Brooks T, Pope D, Marcolini M. Airfoil Self-Noise and Prediction, NASA Reference Publication 1218; 1989

[14] Brooks TF, Marcolini MA. Airfoil tip vortex formation noise. AIAA Journal. Feb. 1986; 24(2):246-252 
